\title{
Caring Experience of Primary Family Caregiver in Elderly with Dementia at Indonesian Rural Area
}

\author{
Muhammad Rosyidul 'Ibad ${ }^{1 *}$, Ahsan Ahsan ${ }^{2}$, Retno Lestari ${ }^{3}$ \\ ${ }^{1}$ Department of Nursing, Faculty of Health Sciences, University of Muhammadiyah Malang \\ ${ }^{2}$ Nursing Master Program, Medical Faculty, University of Brawijaya. \\ ${ }^{1}$ Jalan Bendungan Sutami No.188A, Malang, JawaTimur 65145, Indonesia \\ *Corresponding author: muhammadrosyidulibad@gmail.com
}

\begin{abstract}
Background: Primary family caregiver (PFC) is the nearest person whose main function is the care of elderly dementia at home, before care elderly dementia they require essential preparation, the first is preparation of mentally and the second is preparation in environment. Not all family members willing to care for them, only PFC has a sincerity that is capable to take care of them.Objective: In fact the PFC is not only busy with taking care of elderly dementia alone, but they also have other roles and functions in their families. Some consequences of PFC became the spirit of researchers to explore caring experience of primary family caregiver in elderly with dementia at rural area in Indonesia. Methods: The researchers used a qualitative design with interpretive phenomenological approach, the retrieval of data using in-depth interviews with semi-structured interview guide and field notes.Results: This research resulted in three themes (1) primary family caregiver's barrier in taking care elder with dementia (2) intervention of PFC in taking care elder with dementia (3) Strength of PFC in taking care elder with dementia. Conclusion: PFC in caring for elderly dementia at home the fact is not easy, the efforts taken by the PVC in order to recover dementia being pseudo hopes for PFC in the countryside because progress of disease that slowly got worse in addition plus the lack of exposure to health information.
\end{abstract}

Keywords: Caring Experience, Primary Family Caregiver, Dementia

\section{INTRODUCTION}

The aging process in the elderly is a normal life cycle, where the degenerative process occurs. One is the abnormal changes of dementia. Dementia is a syndrome, chronic or progressive, which is caused by a variety of brain illnesses that affect memory abilities, thinking, behavior and ability to perform activities of daily living (WHO, 2012).

The person closest to the elderly in the community of course is a member of the family. It poses the primary family caregiver as a primary care provider if there are health problems (WHO, 2012). Families need two important things in caring for the elderly with dementia, the first is the mental preparation and the second environments preparations. (Touhy 2005),

Primary family caregivers in addition to having a caring role, they also have certain roles and functions within the family system. At the time of the primary family caregiver return to work in a state of fatigue then coupled see deviate situation in elderly dementia, it can raise the peaked stress response and is manifested by scolding the elderly, and this condition is repeated 
and occurs within the family every day. Caring for a family member with dementia require intensive care and monitoring, in addition to be primary family caregiver has a lot of consequences that will be faced. Based on previous studies have identified that there are three consequences of the impact of treatment when the family had to care for elderly people with dementia is a financial impact, social, and psychological (Brodaty, Donkin, \& Grad 2009). Vugt \& Verhey (2013) explained that the family feel frustrated and overwhelmed when caring for the elderly with dementia, but they still do so by reason of compassion and returning the favor to their parents, to desire a new hope of their parents health regaining.

There are choices for families to care for elderly people with dementia in hospital, in order to obtain good quality health services that can help the healing process. However, these expectations are not easily achieved if only rely on a hospital without the support and involvement of the family directly. According to Jurgens, Clissett, Gladman, \& Harwood (2012), families often complain about the quality of health care provided to dementia, there is dissatisfaction care of patients with dementia, hospital services often bring bad experience, the provision of unrealistic expectations in clients with dementia, and communications are less therapeutic from caregivers in the public hospital.

From some of these phenomena, caring for the elderly with dementia is a condition of a dilemma with all the consequences that obtained by the family. Do families caring for elderly people with dementia at home or whether it will take him to the health service alone. If primary family caregiver are not able to control the negative impact of caring for the elderly with dementia, as well as the various other problems in the family that accumulates, the function and potential of families will decrease and in these conditions prone to arise boredom, frustration, burden, and stress experienced by the primary family caregiver. Their family problems caused by caring for the elderly with dementia, become the spirit of researchers to conduct research, however, because the primary function caregiver implemented to the family. Researchers are interested to explore the life of the PFC in the rural area, what moves their hearts to care for elderly people with dementia at home.

\section{METHOD}

The design of this study was using qualitative interpretive phenomenology approach, the process of data collection was done using in-depth interviews with semi-structured interview guide for 45-60 minutes recorded using Digital Voice Recorder (DVR) with the help of field notes for notes that cannot be recorded with the sound recording device. Participants involved in this research is the main family members caring for the elderly with dementia in Jombang Regency, Indonesia. Determination of the number of participants in the qualitative study an average of less than 10 with the principle of saturation of data (Polit \& Beck, 2012). Data have been obtained will be transcribed and then analyzed by Van Manen Phenomenological Method. Researchers have gained ethical feasibility of the Faculty of Medicine University of Brawijaya 296 / EC / KEPK-S2 / 05/2015

\section{RESULT AND DISCUSSION}

The process of interpretive analysis is performed to find the meaning of a sentence that appears, starting from the selection of the next key sentence define the category, sub-themes, sub-themes to find a theme. Three themes have been identified from the results of this study, 
among other themes: (1) The difficulty of caring for the elderly at home (2) The complexity of routine maintenance, (3) PFC motivation todo daily care activities

Table 1 Analysis of thematic difficulty of caring for the elderly with dementia at home

\begin{tabular}{|c|c|c|}
\hline Sub-Sub-Theme & Sub-Theme & Theme \\
\hline Behavioral Impairment & \multirow{3}{*}{$\begin{array}{l}\text { Elder with dementia conditions } \\
\text { change, past - present }\end{array}$} & \multirow{11}{*}{$\begin{array}{l}\text { The difficulty of caring } \\
\text { for Elder with dementia } \\
\text { at home }\end{array}$} \\
\hline Physical impairment & & \\
\hline Cognitive impairment & & \\
\hline Conflict with other family & \multirow{3}{*}{ A low socioeconomic support } & \\
\hline Cost of treatment is uncertainly & & \\
\hline Limited guarding & & \\
\hline $\begin{array}{l}\text { Less iinformation about dementia } \\
\text { syndrome }\end{array}$ & \multirow{3}{*}{$\begin{array}{l}\text { Familiy confusion to the } \\
\text { treatment }\end{array}$} & \\
\hline Family not knowing the correct treatment & & \\
\hline $\begin{array}{l}\text { The family considers that the drug is less } \\
\text { effective }\end{array}$ & & \\
\hline The house is less secure & \multirow{2}{*}{$\begin{array}{l}\text { Physical environment at home } \\
\text { is at risk }\end{array}$} & \\
\hline The use of a less precise instrument & & \\
\hline
\end{tabular}

The treatment is performed by PFC in elderly dementia at home is not easy, often caregivers feel troubled when caring for the elderly with dementia at home, in this theme was everything that become a barrier on the treatment process which influenced the final result. This theme has four sub-themes, the first of which changes in the conditions experienced by elderly dementia past and present, participants revealed that the elderly dementia tend to behave their own way become complication to the care, elderly dementia also often do not realize what they have done, it also makes the reason that extra attention and supervision required by the caregiver, if it does not like it then it is certain behavioral conditions of elderly with dementia will increasingly unfocused. The elderly dementia must be having cognitive problems that are increasingly declining slowly and surely, the participants explained that they often forget about things that other people sometimes become important.

The second sub-theme is the low socioeconomic support, caring for the elderly dementia is not enough with good mental and physical conditions, the primary family caregiver must also have the financial strength, this is important because it will be useful to support all routine maintenance needs, especially with the other emergent needs of elderly dementia.

The third sub-theme is a family confusion to the treatment, PFC actually have a strong curiosity about how the healing process and treatment of dementia issues directly from health workers, because it is a phenomenon that occurs families with dementia in the community more and more. PFC considers that the need for the need for information about dementia care when at home, especially after treatment in hospital, the education provided is also lacking, education is only given a fixed importance of taking the medication, even though the actual longest treatment is at home. It is important for nurses to provide implementation strategies in families with dementia, where there is a therapeutic element that stimulates cognitive ability and control the deviant behavior of elderly dementia. Nurses have to think wisely, patience is indeed no limits but do not also forget that the coping abilities of each PFC is different.

The fourth sub-theme is the physical environment in the home at risk. PFC stated that required considerable environmental lighting conditions and also avoid places where there is lots 
of objects that can be difficult for the elderly steps when walking. The condition of the neighborhood is also a barrier PFCs in the care of elderly dementia. Slippery floor conditions that make the elderly with dementia often fall add another problem for the caregiver in performing his daily care.

Table 2 Analysis of thematic complexity of routine maintenance

\begin{tabular}{|c|c|c|}
\hline Sub-Sub-Theme & sub-Theme & Theme \\
\hline Provide safety and comfort & \multirow{5}{*}{ PFC cared directly } & \multirow{11}{*}{$\begin{array}{l}\text { The complexity of } \\
\text { routine maintenance }\end{array}$} \\
\hline Physical needs & & \\
\hline Directing to the spiritual activities & & \\
\hline Attention to the feelings of LD & & \\
\hline Controlling the mind of LD & & \\
\hline Provide information about routine care at home & \multirow{2}{*}{$\begin{array}{l}\text { Train the household } \\
\text { assistant }\end{array}$} & \\
\hline Involve household assistantdirectly & & \\
\hline Disturbance role in the family & \multirow{4}{*}{$\begin{array}{l}\text { The negative impact of } \\
\text { the LD at home }\end{array}$} & \\
\hline Decreased income & & \\
\hline Physical exhaustion & & \\
\hline Burdened feelings & & \\
\hline
\end{tabular}

Families who have a family member with dementia at home doing maintenance action in response to the presence of something that needs are not fulfilled, however, care needed by elderly dementia is complex so causing a negative impact on PFC, there are three sub-themes within this theme. First subtheme is PFC care for elderly dementia directly, this means that the PFC as a major determinant that regulates the activities of home care, their weakness that occurs in elderly people with dementia where they cannot determine or decide on a choice, hence its needs PFC to takes over or determine for daily treatment directly.

Second subtheme is PFE train household assistant, it means that the participant has provided understanding and teaching simple treatment techniques that can be done by others to fulfill the needs of the elderly with dementia at home, PFA take anticipatory acts if at any time they cannot function as executing daily routine maintenance of the elderly with dementia, then there will be others who are able to provide temporary care.

Third subtheme is the negative impact of their elderly at home, PFC had said that they were confused when they have to choose to keep taking care of elderly people with dementia at home or prioritize outdoor activities, these conditions will make the dilemma, especially if associated with a role in the family which must choose among still working or did care for the elderly with dementia at home, because the character is indeed require full attention. Family income is reduced because of their great love for the elderly with dementia, primary family caregiver does not want something bad happen to her mother and feel guilty if things happen that are not desirable because after all there is a duty of a child to care for her mother, such as the mothers duty to care for her children. Elderly dementia with impaired mobilization resulted in PFC often lifted up them when they have to move from one place to another, for example from a bed to a wheelchair when she had a shower. This raised the activity takes place every day, so PFC complained of waist pain. If it happens continuously it will cause physical problems such as Low Back Pain. Burdened feelings which have been felt PFC appears when doing outdoor activities, but on the other hand they also have the responsibility to perform routine maintenance on the elderly with dementia at home, the condition of a dilemma like this felt quite confusing 
for the primary family caregiver because they have to choose, and when outside the home they are worried because they keep thinking about the condition of the elderly with dementia at home.

Table 3 Analysis of thematic causal of PFC to do daily care activities

\begin{tabular}{|c|c|c|}
\hline Sub-Sub-Theme & Sub-Theme & Theme \\
\hline Personal spirituality & \multirow{7}{*}{ PFC internal strength } & \multirow{13}{*}{$\begin{array}{l}\text { Causal of PFC to do daily care } \\
\text { activities }\end{array}$} \\
\hline Good time management & & \\
\hline PFC mental strength & & \\
\hline PFC physical strength & & \\
\hline Form of reciprocation of PFC & & \\
\hline A sense of compassion & & \\
\hline As a form of liability & & \\
\hline Cooperation among family & \multirow{3}{*}{ PFC external strength } & \\
\hline Coordination & & \\
\hline Neighbors who oversee & & \\
\hline Increased affection to LD & \multirow{3}{*}{ Getting wisdom when caring LD } & \\
\hline Forms of self-introspection & & \\
\hline Learning for the families & & \\
\hline
\end{tabular}

PFC in caring for the elderly with dementia at home is not easy, but they still do it because of the causal of PFC in carrying out daily maintenance, it means that there is anything that can help facilitate the activities of elderly care with dementia and move the hearts of PFC to keep taking care of them. There are three sub-theme within this theme, the first is the internal strength of PFC, strengthening against themselves, it is important to do so there is a confidenceintaking care. Ability to holds a principle in life is important because caregivers can provide great motivation, a sense of love for the elderly with dementia are useful as medicines when boredom and burnout have felt by PFC. PFC has stated that in the treatment becoming important thing to be able to divide their time between the interests of the elderly with dementia and family, therefore the required a good cognitive abilities in performing time management.

The second sub-theme is the external force obtained by PFC, they can involve their family members during the process of treatment, it is important that the caregiver does not feel overburdened and as anticipatory acts if a caregiver is currently unable to perform its function then temporarily be replaced by other family members. Siblings or other family members can also be used as a source of support. When PFC has importance that cannot be abandoned and require a relatively long time, then the help of the relatives who can be used. PFC can tell difficulties when caring tothe neighbor or close friend that can trust and hope occurs an exchange of ideas that are useful for the caregiver. Someone will be relieved if it was able to tell the difficulty experienced, and they need people who are able to listen, but that needs to be emphasized is that not everyone can afford to be invited to tell each other, only the person who have close ties and trustworthy who can be invited to exchange ideas with PFC.

The third sub-theme is the wisdom that is felt by the PFC. Strengthening against its own PFC self is important so that there is a confidence in caring. Ability to holds a principle in life is important because caregivers can provide motivation. Be patient also provide a positive influence on the mentality of PFC themselves until they are able to synthesize a current 
circumstances then find the meaning of their actions is not in vain, so wisdom or benefit will come when PFCs have open minds and internalize the positive thoughts that to heart which is then performed with a sincere act to care for them until they are still able to care for elderly dementia with varying complexity that can happen at any time.Caring for the elderly with dementia need guidance, experience, and support from various parties who are experts in the field of mental health nursing. Caring for the elderly with dementia is basically a condition that is difficult to deal with each person, but that needs to be emphasized is not to find other complications that continues to grow.

Azermai (2015) states that the anti-psychotic treatment in the elderly who have psychological behavioral symptoms of dementia is complex, this is because the management of anti-psychotic controversial because it has limited effectiveness but are at risk of serious side effects. Psychotic atypical anti-drug such as risperidone and olanzapine there are effects for aggression and psychosis, but the evidence for the efficacy of psychological behavioral symptoms of dementia itself is not convincing (Ballard\& Waite, 2006).

Research conducted by Ducharme, et al (2014) found $70 \%$ of primary caregivers of elderly dementia states (1) lack of information on assistance and financial resources (2) requires a relative who is able to appreciate and be able to offer assistance as their ability (3) take actions that can reduce the stress resulting from the role as caregiver and need more time for theirselves (4) need help at the right time and the type of assistance according to the situation.

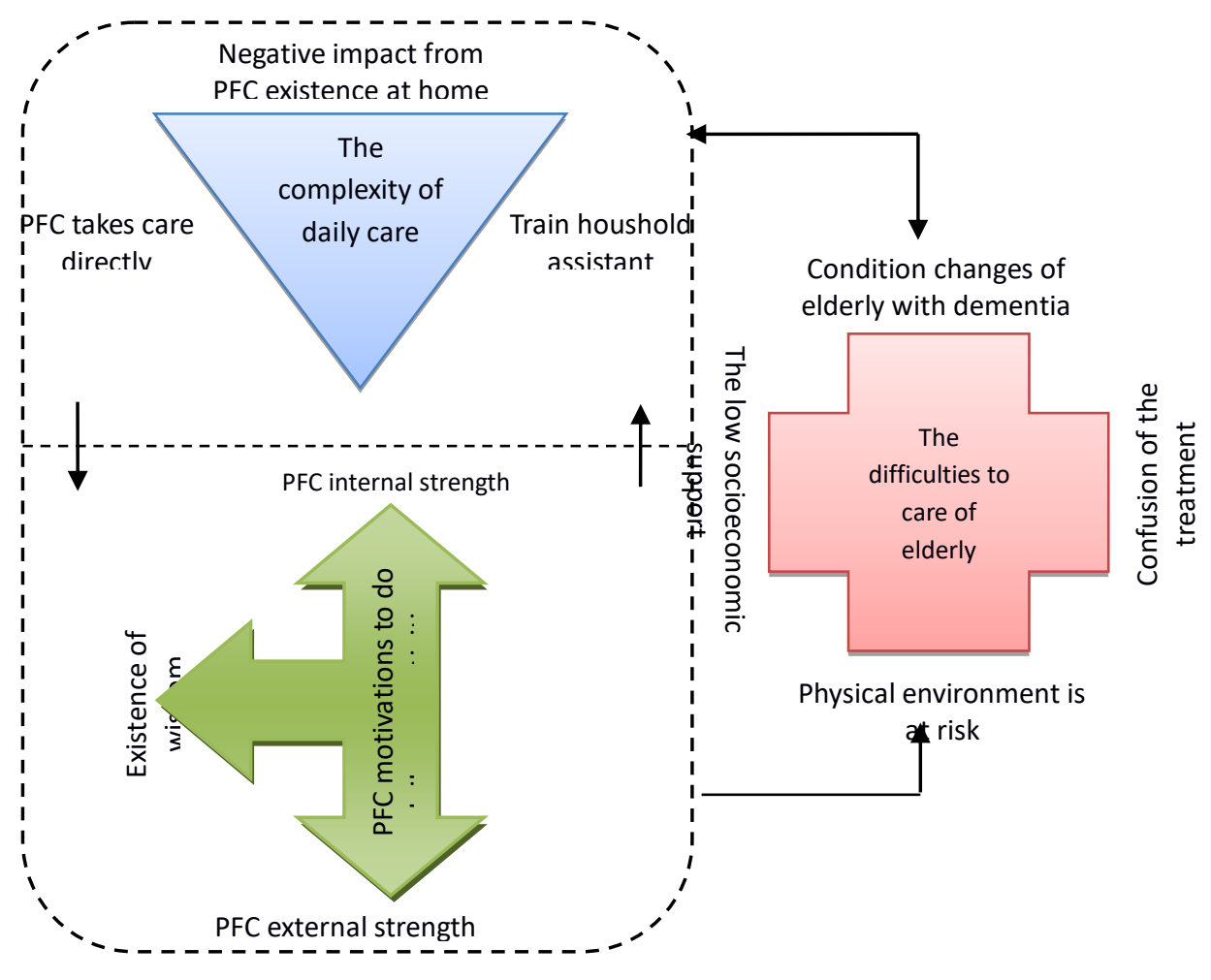

Figure 1 Themes linkage

The meaning of the complications of dementia in elderly care in the daily care of primary family caregiver certainly encounter the difficulties that may impede the process of caring for the 
elderly with dementia, of course, this will also have an impact on the results of the treatment. The emergence of complications disclosed primary family caregiver can be used as an opportunity to identify what kind of support can be given as a solution to minimize the complications that arise.Based on the research that the act of PFCs in their daily activities is a core role, which provides daily care needs, supervise, determine treatment, and protect the elderly with dementia. Researchers have found out the linkages between the themes that have been obtained based on the results of research, these linkages can be seen in figure 1 .

Researchers have found all of what they are doing is not without reason, the primary family caregiver do so because there is a strong impetus is the reason that up to now they are still doing the home care. This is evidenced by their sense of duty, felt sorry for the condition of elderly dementia, a sense of reciprocation for elderly dementia formerly also been sacrificed for him, as well as their religious motives which religion provides the appropriate consequences of behavior done while in the world. Research conducted Stephan, et al (2015) in Germany studied the success of the collaboration between informal caregiver with a professional health care. Still there is a discrepancy between the informal caregivers and professional health care. The initial contract of both remains a major challenge, on the other side of health care professionals expect to be informed but informal caregiver still feel hesitant to ask for help, especially since the inner barrier. Substantivelythe feelings of empathy between the two caregivers can be the bridge that facilitates collaboration.

\section{LIMITATIONS}

The results of this study illustrate the condition of elderly dementia caregivers, specifically, cannot be generalized and not classified in accordance with the degree of dementia syndrome, and not by disease causes so that the possibility of manifestation of reported PFC picture becomes quite diverse.

\section{CONCLUSION}

The presence of the elderly with dementia in the family is a challenge for the family, there are many complications that can be perceived by PFC in connection with changes in the conditions experienced by the elderly with dementia, hence PFC still have a sense of responsibility in their care at home despite some impact on the PFC often arise. In carrying out home care would need major impetus from within self, family, and others outside the family.

\section{REFERENCES}

Azermai, M. (2015) Dealing With Behavioral and Psychological Symptoms of Dementia: A General Overview. Dovepress. Psychology Research and Behavior Management (8) 181185

Ballard C \& Waite J. (2006). The Effectiveness of Atypical Antipsychotics for the Treatment of Aggression and Psychosis inAlzheimer's disease. Cochrane Database Systematic Review.

Brodaty, H., Donkin, M., \& Grad. (2009). Family Caregivers of People with Dementia. Dialogues in Clinical Neuroscience, 11(2), 217-228.

Ducharme F, Kergoat M.J., Coulombe R, Lvesque L., Antonie P., \&Pasquier F. (2014) Unmet Support Needs Of Early-Onset Dementia Family Caregivers: A Mixed-Design Study. BMC Nursing 13:49 
Jurgens, F. J., Clissett, P., Gladman, J. R., \& Harwood, R. H. (2012). Why are Family Careers of People with Dementia Dissatisfied with General Hospital Care? A Qualitative Study. BMC Geriatrics, 12(57), 1-10.

Polit, D. F., \& Beck, C. T. (2012). Nursing Research Generating and Assessing Evidence for Nursing Practice (9th Ed.). Philadelphia: Wolters Kluwer Health | Lippincott Williams \& Wilkins.

Stephan A, Mohler R, Guiteras A.R., \& Meyer G. (2015). Successful Collaboration in Dementia Care fromthe Perspectives of Healthcare Professionals and Informal Carer'sin Germany: Results froma Focus Group Study. BMC Health Services Research 15:208

Touhy, T. (2005). Gerontological Nursing \& Healthy Aging (2nd ed.). Philadelphia Mosby Elsevier Inc.

Vugt, M. E. d., \&Verhey, F. R. J. (2013). The Impact of Early Dementia Diagnosis and Intervention on Informal Caregivers. Progress in Neurobiology, 110(2013), 54-62.

WHO. (2012). Dementia A public health priority. Retrieved 19 march, 2014, from,http://www.who.int/mental_health/publications/dementia_report_2012/e 